\title{
Inhibition of naming by rhyming primes
}

\author{
GEORGIJE LUKATELA and M. T. TURVEY \\ University of Connecticut, Storrs, Connecticut \\ and Haskins Laboratories, New Haven, Connecticut
}

\begin{abstract}
The priming effects of graphemically similar (e.g., HOSE) and graphemically dissimilar (e.g., ROws) rhymes on the naming of target words (NOSE) were examined at prime-target stimulus onset asynchronies (SOA) of 36,70 , and $250 \mathrm{msec}$. A four-field presentation procedure was used of mask-primemask-target. The effects of rhyme primes were measured relative to those of nonrhyming control primes (CHEF, DISH) that matched the rhymes in frequency and length and shared no letters in the same positions. At SOAs of 36 and $70 \mathrm{msec}$, rhyme priming was inhibitory and equal for graphemically similar and graphemically dissimilar rhymes. At SOA $=250 \mathrm{msec}$, rhyme priming was insignificant with a tendency toward facilitation. The results are discussed in the context of (1) contrasting effects of complete versus partial phonological overlap within a prime-target pair, and (2) the hypothesis that phonological codes stabilize fastest and provide, therefore, the earliest and major constraint on word recognition.
\end{abstract}

Do rhymes prime? That is, is the perception of NOSE affected by the prior presentation of Rows? The question is significant in the context of theories of word recognition and lexical memory. A visually presented word can be coded with respect to how it looks (its orthographic structure), how it sounds (its phonological structure), what it means (its morphological and semantic structure), and how it performs (its syntactic roles). When two words are presented in close succession, the facts of shared or contrasting dimensions of similarity mean that the coding of the first can have consequences for the coding of the second. Rows differs from NOSE visually, semantically, and syntactically, but it is very much like NOSE phonologically. If words in lexical memory are stored by or with phonological codes, or if prelexical processes include forming a word's phonological code in order to access lexical memory, or both, then the visual presentation of Rows shortly before the visual presentation of NOSE should affect NOSE despite its differences in visual form, semantic content, and syntactic function.

Experimental inquiry into rhyme priming in English has provided a mixed bag of results. Hillinger (1980) reported reliable priming for both HOSE-NOSE and ROWSNOSE. However, under closely similar conditions of clearly perceptible primes and targets, Martin and Jensen (1988) found no priming by either HOSE or ROWs in lexical decision, and Peter, Lukatela, and Turvey (1990) found no priming by either HOSE or NOSE in naming, in experiments in which the prime-target stimulus onset asynchrony (SOA) exceeded $500 \mathrm{msec}$. In a naming experiment with unidentifiable primes and an SOA of $60 \mathrm{msec}$, Forster and Davis (1991) found no priming by

Correspondence concerning this article should be addressed to G. Lukatela, Haskins Laboratories, 270 Crown St., New Haven, CT 06511-6695 (e-mail: lukatela@uconnvm.uconn.edu).
Rows but did find facilitation by nonrhyming primes that shared the initial sounds of their targets. A variety of outcomes, some of which stand in contrast to the preceding, were reported by Lupker and Colombo (1994). They found that orthographically similar rhymes could facilitate, inhibit, or have no effect whatsoever, depending on other factors. At an SOA of $315 \mathrm{msec}$, and with identifiable primes, Lupker and Colombo found inhibition effects for highfrequency (HF) targets and facilitation for low-frequency (LF) targets in "irregular" prime-target pairs (BLOODFLOOD). For "regular" pairs (ARM-FARM), they did not find any effect (either facilitatory or inhibitory) in naming and only weak facilitation with LF targets in lexical decision. Lupker and Colombo did not examine the effects of orthographically different rhymes (ROWS-NOSE). These effects were examined, however, by Bowey (1993), who compared orthographically different rhymes such as IRLCURL with orthographically similar rhymes such as AITBAIT. Bowey (1993, Experiment 3) found that the difference in naming latencies between BAIT unprimed and BAIT preceded at an SOA of $300 \mathrm{msec}$ by AIT was significantly greater than the difference between CURL unprimed and CURL preceded at an SOA of $300 \mathrm{msec}$ by IRL. However, the conclusion that this outcome indicates strong priming by orthographically similar rhyme primes and weak priming by orthographically dissimilar rhyme primes is compromised by the fact that nonprimed latencies to BAIT and CURL differed by $32 \mathrm{msec}$ ( $575 \mathrm{vs} .543 \mathrm{msec}$, respectively) in contrast to the primed latencies, which differed by only $6 \mathrm{msec}$ ( $527 \mathrm{vs.} 521 \mathrm{msec}$, respectively). In short, in Bowey's experiment, possible ceiling effects and limited room for improvement in the set of stimuli exemplified by CURL biased the outcome against the IRL-CURL stimuli.

In sharp contrast to inconsistent priming by identifiable rhymes are demonstrations of phonological priming of English words by identifiable homophones (KNOWS- 
NOSE) and pseudohomophones (NOZE-NOSE) at SOA = 250 msec by Lukatela and Turvey (1994b). Unlike rhyme primes, which share only partially the phonology of their targets, homophones and pseudohomophones possess exactly the phonology of their targets. In the present article, we presume that this contrast of primes that overlap partially (only in rhyme) and primes that overlap fully (in both onset and rhyme) with the phonology of their targets is the key to understanding the elusive nature of rhyme priming relative to the reliable nature of homophonic and pseudohomophonic priming.

\section{The Phonological Coherence Hypothesis}

The phonological priming results (Lukatela \& Turvey, 1994b), and others of like kind, showing early, orthographically indifferent effects of phonology on naming (e.g., Lukatela \& Turvey, 1994a), letter identification (e.g., Perfetti, Zhang, \& Berent, 1992), and semantic category judgments (e.g., Van Orden, 1987) are consistent with the phonological coherence hypothesis (Van Orden \& Goldinger, 1994; Van Orden, Pennington, \& Stone, 1990). According to this hypothesis, the orthographicphonological activation dynamics stabilize earliest in visual word recognition, providing a basis for stabilizing the other patterns of linguistic activation, and providing the earliest available constraint on lexical dynamics via a phonological-semantic network. The basis for phonology's leading role lies in covariant learning (Van Orden et al., 1990). The spellings of words and the names of words covary to a high degree and do so almost perfectly in some languages. This high covariation means strong connection weights between each of a word's orthographic subsymbols and each of its phonological subsymbols. The mappings between orthography and word meanings, phonology and word meanings, orthography and the syntactic functions of words, and so on, are less consistent. The upshot is that although several linguistic substructures may be activated concurrently by orthographic substructures in word recognition, the phonological substructures achieve dynamic resolution earliest and exert the dominant influence on word recognition.

The phonological coherence hypothesis is expressed within a general resonance framework. A network exhibits "resonance" to the degree that its upward and downward flows of activation are mutually reinforcing (Grossberg, 1980; Van Orden \& Goldinger, 1994). For example, the pattern of activation fed upward from orthographic subsymbols through a bottom-up matrix of connections creates a pattern of activation in linguistic subsymbols which, in turn, feed activation back downward through a matrix of top-down connections. Wherever the downward flow of activation matches the initial orthographic activation, there is a conservation of bottom-up activation by top-down activation, meaning that the orthographic pattern has the ability to reactivate the linguistic pattern, and it, in turn, the ability to reactivate the orthographic pattern, and so on (Van Orden \& Goldinger, 1994). A similar account can be given of the phonology semantic and orthography-semantic networks. Reso- nances in these networks are achieved when the flow upward from the phonological activation and orthographic activation, respectively, is matched by the flow downward of semantic activation. A key feature of the phonological coherence hypothesis is that orthographic-semantic resonance is achieved slowest and relies upon the resonances involving phonology.

\section{Loci of Phonological and Rhyme Priming}

Within the orthographic-phonological network, phonological priming would arise as phonological activitation by the prime (KNOWS, NOZE) that is fully consistent with phonological activitation by the subsequent target (NOSE). Orthographic priming could also arise as orthographic activitation by the prime that is largely consistent with orthographic activitation by the subsequent target. That is, orthographic priming is related to the specific encodings (orthographic subsymbols, connections) leading to particular phonological patterns, and phonological priming is related to the particular active phonological patterns themselves. The latter two comments are reminiscent of the encoding-bias hypothesis introduced in the original examination of these priming effects by Meyer, Schvaneveldt, and Ruddy (1974).

If the persistence of orthographic activitation is less than that of phonological activation, then orthographic priming should be absent at SOAs at which phonological priming persists. Experimental observations suggest time scales at which the two primings of different origins co-occur, and (longer) time scales at which the priming is only phonological (Ferrand \& Grainger, 1993, 1994; Lukatela \& Turvey, 1994b). Additionally, if orthographic processing units become substantially active before their corresponding phonological processing units, then orthographic priming at very short time scales should be at least equal to phonological priming (Lukatela \& Turvey, 1994b) and may possibly exceed phonological priming (Ferrand \& Grainger, 1993).

Within the framework of the phonological coherence hypothesis, phonological priming can arise through an additional source. Gradually and simultaneously with its evolution in the orthographic-phonological network, the phonological representation for KNOWS or NOZE will activate through the phonological-semantic network a number of homophonic lexical processing units, including the representation nose. An activated lexical processing unit sends (1) activating signals to its lexical neighbors, and (2) positive feedback to the phonological layer. The ensuing top-down activation by these semantic subpatterns will match the phonological activation. Consequently, when the target NOSE is presented, the resonant state of the phonological-semantic network arising from prime processing will be highly compatible with the processing of NOSE. The upshot is that both the orthographic-phonological and the phonologicalsemantic networks are prepared for the processing of NOSE by the primes KNOWS and NOZE.

Rhyme priming (where only the rhyme is shared) should be addressed in the same way as phonological priming 
(where both onset and rhyme are shared). Within the orthographic-phonological network, HOSE and ROWS should induce activation of some orthographic and phonological subpatterns in common with the target, providing a basis for facilitation. Within the phonological-semantic network, however, the resonances arising from processing HOSE and ROWS - resonances involving semantic subpatterns very different from those of NOSE-could be sufficiently incompatible with the processing of NOSE as to provide a potential basis for inhibition. If the target is to be named, and naming is based on the state of the phonological level, then resonance reinforcing the phonological code $/ \mathrm{hoz} /$ or $/ \mathrm{roz} /$ could impede the establishment of the requisite phonological code /noz/.

Inhibition at short prime-target SOAs is similarly expected from the model proposed by O'Seaghdha and colleagues (O'Seaghdha, Dell, Peterson, \& Juliano, 1992). Onset of the prime activates the prime's phonological representation and creates an episodic memory of the orthographic subpatterns and phonological subpatterns coactivated by the prime. A rhyming target following closely on the heels of the prime raises the level of activation in the prime's lexical representation and reinvigorates the prime's episodic memory with a resultant amplification of the prime's phonological code. The process of resolving the target's phonological representation, therefore, takes place against the background of a strongly competing representation of the prime's phonology. In consequence, the establishment of the target's phonological code is slowed.

In sum, there are theoretical reasons for assuming that the influence of a rhyming prime on its target will be inhibitory at brief SOAs. Evidence for such inhibition is sought in the experiments of the present article.

\section{EXPERIMENT 1}

In order for our investigation of rhyme priming to provide data relevant to the conjecture that such priming is fundamentally inhibitory, it must countenance two major points of methodology. First, it must minimize the potentially facilitative contributions of orthographic dimensions of similarity, and second, it must control for differences among the primes that are extraneous to the theoretically significant differences in phonology and orthography.

Our interpretation of orthographic priming (roughly, the priming based on graphemic similarity between prime and target) is that it occurs when the target's moment of presentation is encompassed by the time scale over which activity persists in the orthographic processing layer. Fast-acting phonological effects, those manifest experimentally at very brief prime-target SOAs, could well occur within a time scale that overlaps the time scale of orthographic persistence. Consequently, in order to study these phonological effects contaminated minimally by orthographic persistence, a procedure is needed that either curtails orthographic persistence or renders it nonspecific (noiselike). Lukatela and Turvey (1994b) suggested that an appropriate procedure is provided by preceding the prime by one pattern mask and inserting a second pattern mask into the prime-target SOA (see also Humphreys, Besner, \& Quinlan, 1988). ${ }^{1}$ This intervening mask procedure was used in Experiment 1 , with primes in uppercase and targets in lowercase.

In the study of rhyme priming, differences among the primes in the stimulus pairs defining identity priming, graphemically similar rhyme priming, and graphemically dissimilar rhyme priming, are rarely just differences in their orthographic and phonological relation to the target. They tend to differ additionally in frequency and their relative visual similarity to the target. The significance of controlling for these differences cannot be undervalued. Consider prime frequency, for example. Equating the frequencies of identity primes, graphemically similar rhyme primes, and graphemically dissimilar rhyme primes is difficult, if not impossible, for any reasonably large number of experimental stimuli. Models of word recognition commonly assume that a word's frequency dictates one or all of the following: the word's rate of encoding, the latency of achieving a supraliminal activation level in lexical representation, and the degree of inhibition that its active lexical representation attracts in competition with other representations. Consequently, given the target NOSE, a comparison between graphemically similar and graphemically dissimilar primes (e.g., between HOSE and ROWS) could be contaminated by a difference between these primes in frequency-especially at the short SOAs where the effect on priming of processing time differences is likely to be most pronounced.

In addition to controlling for differences in frequency and visual similarity, the requisite experimental design should permit a reliable and sensitive measure of the magnitude of priming by each of the so-called identity, graphemically similar rhyme, and graphemically dissimilar rhyme primes. Consequently, in Experiment 1, a given target word (nose) was combined in a counterbalanced manner with three different experimental primes and their individual controls. For example, the experimental primes for nose were NOSE, HOSE, and ROWS, and their respective control primes were DUTY, CHEF, and DISH, respectively. Each control prime was chosen to be identical in frequency to its corresponding experimental prime and to contain no letters in common in the same position.

In Experiment 1, the sequence of stimuli was as follows: pattern mask $(500 \mathrm{msec})$, prime $(18 \mathrm{msec}$, presented in uppercase), pattern mask (18 msec), target (400 msec, presented in lowercase), with interstimulus intervals (ISIs) of $0 \mathrm{msec}$. The majority of prime-target pairs (over two thirds) were nonrhyming. It was expected that, if rhyme priming is inhibitory, and if homophonic priming is facilitatory, then under these timing and masking manipulations (1) HOSE-nose should produce slower naming than should CHEF-nose, (2) ROWS-nose should produce slower naming than should DISH-nose, (3) the two differences, 
HOSE-nose < CHEF-nose and Rows-nose < DISH-nose, should be identical, and (4) NOSE-nose should produce faster naming than should DUTY-nose.

Experiment 1 reproduces the design details of Lukatela and Turvey's (1994b) Experiment 7 with one exception - the replacement of pseudohomophone primes by rhyme primes. In their Experiment 7, Lukatela and Turvey found a 12-msec facilitation (significant by both subjects and items). This facilitatory outcome under the identical temporal and masking conditions of the present experiment provides, therefore, an appropriate benchmark for the current expectation that rhyme priming, unlike homophonic and pseudohomophonic priming, is initially (i.e., in the earliest stages of word processing) inhibitory.

\section{Method}

Subjects. Fourty-eight undergraduates at the University of Connecticut served as subjects in Experiment 1. A subject was assigned to one of six groups, according to the time he/she arrived at the laboratory, to give a total of 8 subjects per group.

Materials. The stimuli consisted of 72 groups of three contexttarget pairs of English rhyming words, with each pair in a group of three having the same target word (e.g., SUN-sun, BUN-sun, TON-sun). List 1 consisted of 72 identity-related prime-target pairs (e.g., SUN-sun, MOLE-mole). Each prime in List 1 was then replaced by its "visually similar" rhyme to produce List 2 , consisting of 72 visually similar prime-target rhyming pairs (e.g., BUN-sun, HOLE-mole). List 3 consisted of 72 visually dissimilar prime-target rhyming pairs (e.g., TON-sun, sOUL-mole).

There were three control lists, Lists 4-6. List 4 consisted of 72 nonidentity (i.e., visually and phonologically unrelated) nonrhyming prime-target pairs (e.g., HIT-sun, DUMP-mole). Each unrelated prime (e.g., HIT, DUMP) was a word that, in relation to its corresponding List 1 prime, (1) had no letters in common (or in rare cases, just one letter, but in a different position), (2) was of the same length (i.e., the same number of letters), (3) was of approximately the same frequency (compare SUN and HIT, MOLE and DUMP), and (4) was not a prominent associate of the corresponding target.

List 5 consisted of 72 control nonrhyming prime-target pairs (e.g., GAB-sun, BUSY-mole). Each nonrhyming prime (e.g., GAB, BUSY) was a word that (1) shared in the same position no letters with its corresponding List 2 prime, (2) was of the same length and frequency as was its corresponding List 2 prime (compare BUN and GAB, HOLE and BUSY), and (3) was not a prominent associate of the corresponding target.

List 6 consisted of 72 control nonrhyming prime-target pairs (e.g., OAR-sun, RING-mole). Each control nonrhyming prime (e.g., OAR, RING) was a word that (1) shared in same position no letters with its corresponding List 3 prime, (2) was of the same length and frequency as its corresponding List 3 prime (compare TON and OAR, SOUL and RING), and (3) was not a prominent associate of the corresponding target.

Finally, in order to minimize development of a possible strategic expectancy, a foil list was assembled consisting of 24 visually similar, phonologically dissimilar context-target pairs (e.g., вомB-tomb, SUIT-suite), and 24 visually and phonologically dissimilar pairs (e.g., PITCH-toad, LOAD-ditch). For all stimulus pairs, the context stimuli were written in uppercase and the target stimuli were written in lowercase.

Each of Lists 1-6 was implicitly divided into two sublists (Sublist A, with mostly HF target words, and Sublist B, with mostly LF target words) of 36 prime-target pairs each. Thus, Sublist A had a mean target word frequency of 216 , and Sublist B had a mean target word frequency of 23. In Sublist A, the mean prime frequencies for List 1 , List 2 , List 3 , List 4 , List 5 , and List 6 were $216(S D=419), 72(S D=151), 34(S D=73), 231(S D=449)$, $73(S D=154), 33(S D=72)$, respectively. In Sublist $B$, the mean prime frequencies for List 1 , List 2 , List 3 , List 4 , List 5 , and List 6 were $23(S D=24), 49(S D=92), 133(S D=267), 23$ $(S D=24), 49(S D=93), 136(S D=287)$, respectively.

Design. A given subject never encountered a given word more than once. This was achieved by using six groups of subjects. There were six basic prime types, defined by Lists $1-6$ (SUN-, BUN-, TON-, HIT-, GAB-, OAR-), and two sublists (Sublist A and Sublist B), providing for each subject six basic experimental situations with 12 stimulus pairs per situation. One half of the pairs from each list was from Sublist A, and the other half was from Sublist B (sublist or frequency was not blocked). In addition, each subject saw a foil set (the same for all subjects) consisting of 24 graphemically similar but phonemically dissimilar word-word pairs (MINT-pint, COUCH-touch) as well as 24 graphemically and phonemically dissimilar pairs (LOAD-ditch, PITCH-toad). In total, a subject saw 120 stimulus pairs, of which 84 were nonrhyming. The experimental sequence was divided into three subsets, with a brief rest after each subset. Stimulus types were ordered pseudorandomly within each subset. Experimental sequence was preceded by a practice sequence of 30 different word-word pairs.

Procedure. The subject sat in front of an Apple Ile monitor in a well-lit room (to help reduce the sharpness of the stimuli on the screen). On each trial, the subject was presented with a sequence of stimuli: a visual mask for $500 \mathrm{msec}$, the prime for $18 \mathrm{msec}$, another visual mask for $18 \mathrm{msec}$, and the target for $400 \mathrm{msec}$. The stimuli followed each other at an ISI $=0 \mathrm{msec}$. Consequently, the SOA was $36 \mathrm{msec}$. (The preceding temporal values were made possible by modifications of the machine code of the Apple IIe).

Each subject was instructed as follows: "First you will see a complex visual pattern consisting of a row of hash marks and various strings of uppercase letters. Then you will see a word written in lowercase letters. The word in lowercase you are supposed to read aloud as fast as you can and as accurately as you can. You should try to ignore the complex visual pattern."

The exposure durations given above are "nominal" rather than exact, because display changes in reality occurred within the standard 16-msec scan rate of the Apple IIe monitor. This means that all actual durations of nominal exposures in the present experiments - and in the other experiments reported in the present article-varied in a random manner with a uniform probability between $+8 \mathrm{msec}$ and $-8 \mathrm{msec}$ around the statistical mean exposure.

In all conditions, latencies from the onset of the target to the onset of the response were measured by a voice-operated trigger relay. Naming was considered erroneous when the target word was mispronounced or preceded by any other sound, the pronunciation was not smooth (i.e., subject hesitated after beginning to name), or the response was not loud enough to trigger the voice key. If the naming latency was longer than $1,000 \mathrm{msec}$, a message appeared on the screen requesting the subject to name more quickly. All latencies, including those longer than $1,000 \mathrm{msec}$, were stored in the computer memory.

\section{Results and Discussion}

In the debriefing, subjects were simply asked whether they had noticed the presence of letters in the displays preceding the target. Their reports were negative in agreement with the pilot work that had established prime masking for the present stimulus conditions at an SOA of $36 \mathrm{msec}$ (see Lukatela \& Turvey, 1994a, Experiment 5). A $3 \times 2 \times 2$ (prime type $\times$ rhyme $\times$ target frequency) analysis of variance (ANOVA) was conducted on naming latencies. (In this ANOVA, prime type refers to a list and 
its control, so that List 1 and List 4, List 2 and List 5, and List 3 and List 6 are the three prime types, and rhyme refers to the contrast between Lists 1-3 and their controls, Lists 4-6. In this omnibus ANOVA, prime type and rhyme are quasi variables with target frequency as a real variable. It provides useful indicators of interactions involving target frequency.) The omnibus ANOVA revealed that the main effect of target frequency (HF $=534 \mathrm{msec}$ vs. $L F=544 \mathrm{msec}$ ) was significant only by subjects $\left[F_{1}(1,47)=35.04, p<.001 ; F_{2}(1,70)<1\right]$. No interaction with frequency was significant $(F<1)$.

The data relevant to the planned comparisons are summarized in Tables 1A-1B and Figure 1. For simplicity, we use one stimulus pair to represent the set of stimuli to which it belongs. Thus, NOSE-nose differed from DUTY-nose by $19 \mathrm{msec}$, which was significant $\left[F_{1}(1,47)=30.96, p<\right.$ $\left..001 ; F_{2}(1,70)=30.29, p<.001\right]$; HOSE-nose was significantly slower than CHEF-nose by $12 \mathrm{msec}\left[F_{1}(1,47)=\right.$ $\left.10.05, p<.01 ; F_{2}(1,70)=14.53, p<.001\right]$; and Rowsnose was significantly slower than DISH-nose by $10 \mathrm{msec}$ $\left[F_{1}(1,47)=11.29, p<.002 ; F_{2}(1,70)=9.70, p<.01\right]$. Additional analyses revealed that both partial interactions involving NOSE-nose were significant by both sub-

Table 1A

Mean Naming Latencies ( $L$, in Milliseconds) and Error Rate (ER, in \%), With the Corresponding Standard Deviations by Subjects and by Items for the Rhyming Primes of Experiment 1

\begin{tabular}{|c|c|c|c|c|c|c|}
\hline & \multicolumn{2}{|c|}{ NOSE-nose } & \multicolumn{2}{|c|}{ HOSE-nose } & \multicolumn{2}{|c|}{ Rows-nose } \\
\hline & L & ER & $\mathrm{L}$ & ER & $\mathrm{L}$ & ER \\
\hline \multicolumn{7}{|c|}{ Sublist A } \\
\hline $\begin{array}{l}M \\
S D\end{array}$ & 518 & 1.74 & 544 & 3.82 & 544 & 3.13 \\
\hline By subjects & 62 & 5.15 & 52 & 7.08 & 58 & 6.57 \\
\hline By items & 35 & 4.38 & 31 & 7.80 & 39 & 8.11 \\
\hline \multicolumn{7}{|c|}{ Sublist B } \\
\hline $\begin{array}{l}M \\
S D\end{array}$ & 525 & 4.17 & 557 & 1.39 & 552 & 3.47 \\
\hline By subjects & 61 & 8.06 & 60 & 4.66 & 55 & 6.84 \\
\hline By items & 36 & 7.32 & 43 & 3.98 & 35 & 6.42 \\
\hline
\end{tabular}

Table 1B

Mean Naming Latencies ( $L$, in Milliseconds) and Error Rate (ER, in \%), With the Corresponding Standard Deviations by Subjects and by Items for the Control Primes of Experiment 1

\begin{tabular}{|c|c|c|c|c|c|c|}
\hline & \multicolumn{2}{|c|}{ DUTY-nose } & \multicolumn{2}{|c|}{ CHEF-nose } & \multicolumn{2}{|c|}{ DISH-nose } \\
\hline & $\mathrm{L}$ & ER & $\mathrm{L}$ & ER & L & ER \\
\hline \multicolumn{7}{|c|}{ Sublist A } \\
\hline $\begin{array}{l}M \\
S D\end{array}$ & 533 & 2.43 & 532 & 1.74 & 536 & 1.74 \\
\hline By subjects & 53 & 5.94 & 50 & 5.15 & 54 & 5.15 \\
\hline By items & 33 & 5.84 & 35 & 4.38 & 37 & 5.31 \\
\hline \multicolumn{7}{|c|}{ Sublist B } \\
\hline $\begin{array}{l}M \\
S D\end{array}$ & 547 & 3.82 & 544 & 0.69 & 539 & 1.74 \\
\hline By subjects & 54 & 7.08 & 58 & 3.37 & 47 & 5.15 \\
\hline By items & 40 & 6.56 & 42 & 2.90 & 35 & 4.38 \\
\hline
\end{tabular}

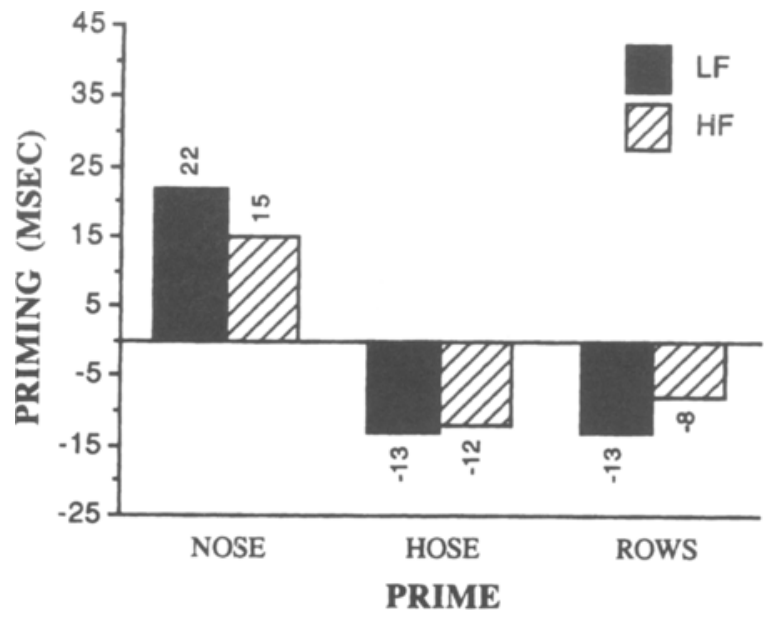

Figure 1. Priming of nose as a function of type of prime and target frequency in Experiment 1.

jects and stimuli (all $F \mathrm{~s}, p<.01$ ). More importantly, the partial interaction between HOSE-nose versus CHEF-nose (-12-msec difference) and ROWs-nose versus DISH-nose ( $-10-\mathrm{msec}$ difference) was insignificant overall (both $\left.F_{\mathrm{S}}<1\right)$ and when analyzed as a function of frequency (all $F_{\mathbf{S}}<1$ ).

In the omnibus error analysis, the main effect of rhyme (rhymes $=2.95 \%$ vs. controls $=2.03 \%$ ) was insignificant by subjects $\left[F_{1}(1,47)=3.76, p>.05\right]$, but it was significant by stimuli $\left[F_{2}(1,70)=4.75, p<.05\right]$. The main effect of prime type was insignificant $\left[F_{1}(2,94)=\right.$ $\left.1.67, p>.05 ; F_{2}(2,140)=1.55, p>.05\right]$. The prime type $\times$ target frequency interaction was significant $\left[F_{1}(2,94)=\right.$ $\left.5.78, p<.01 ; F_{2}(2,140)=4.04, p<.05\right]$; it was insignificant, however, when evaluated for only the graphemically similar and dissimilar rhyming pairs $\left[F_{1}(1,47)=\right.$ $\left.3.08, p>.05 ; F_{2}(1,70)=2.08, p>.05\right]$. Other main effects and interactions in the error analysis were insignificant (all $F \mathrm{~s}<1$ ).

\section{EXPERIMENT 2}

The outcome of Experiment 1 was singularly straightforward: At an SOA of 36 msec (and target duration of $18 \mathrm{msec}$ ), with controls for irrelevant prime differences, and with masking to reduce prime-target interaction at the level of visual features, rhyme priming was inhibitory and of the same magnitude for graphemically similar and graphemically dissimilar rhymes. This outcome is consistent with the understanding that rhyme primes, unlike homophonic primes, have the potential to generate patterns of activity in the phonological layer of processing that can be competitive with the patterns activated by the target. Given the overall insignificance of graphemic similarity, identity priming can be considered primarily as homophonic and semantic priming. Where rhyme priming was inhibitory, homophonic/semantic (identity) priming was facilitatory. Under the same temporal and 
masking conditions as those of the present experiment, Lukatela and Turvey (1994b, Experiment 7) found that pseudohomophones (e.g., TODE) facilitated the naming of their targets (toad). The comparison of Experiment 1 with the results of Lukatela and Turvey's (1994b) Experiment 7 underscores the marked contrast in the earliest phases of the word recognition process between the interactions of rhymes (leading to inhibition) and the interactions of homophones (leading to facilitation).

We have hypothesized that the earliest phases of processing are primarily directed at achieving phonological coherence. We have hypothesized further that in the earliest phases, when a prime's phonology overlaps partially but not fully with the phonology of its target, a kind of competition ensues that retards phonological coherence with respect to the target. The results of Experiment 1 are consistent with both of the preceding hypotheses. Presumably, with the lengthening of SOA we might expect that (1) the inhibitory interaction between rhymes should lessen, (2) unimpeded phonological coherence in respect to the target should increase in likelihood, and (3) other processing factors should begin to make their marks on naming latency. In Experiment 2, the SOA used in Experiment 1 was effectively doubled, from 36 to $70 \mathrm{msec}$. Of interest was whether the orthographic-independent inhibition induced by a rhyming prime would persist and whether a beneficial effect of target frequency would become apparent.

\section{Method}

Subjects. Fourty-eight undergraduates at the University of Connecticut served as subjects in Experiment 2. None had participated in Experiment 1. A subject was assigned to one of six groups, according to the time he/she arrived at the laboratory, to give a total of 8 subjects per group.

Materials. The stimuli were the same as in Experiment 1.

Procedure. The procedure was the same as in Experiment 1, with the exception of the stimulus sequence: a visual mask for $500 \mathrm{msec}$, the prime for $35 \mathrm{msec}$, another visual mask for $35 \mathrm{msec}$, and the target for $400 \mathrm{msec}$. The stimuli followed each other at ISI $=0 \mathrm{msec}$. Consequently, the SOA was $70 \mathrm{msec}$.

\section{Results}

In the debriefing, a majority of subjects reported an ability to see the priming word, at least in part, in the "complex" visual mask that preceded the to-be-named target word. The outcome of the debriefing was in agreement with previous work revealing visibility of the prime under the present masking conditions at a similar SOA of $60 \mathrm{msec}$ (see Lukatela \& Turvey, 1994b, Experiment 6). A $3 \times 2 \times 2$ (prime type $\times$ rhyme $\times$ target frequency) ANOVA was conducted on naming latencies. The omnibus ANOVA revealed that the main effect of target frequency $(\mathrm{HF}=545 \mathrm{msec}$ vs. $\mathrm{LF}=553 \mathrm{msec})$ was significant by subjects $\left[F_{1}(1,47)=22.78, p<.001\right]$, but not by stimuli $\left[F_{2}(1,70)=1.17, p>.05\right]$. The prime type $\times$ target frequency interaction was significant by stimuli $\left[F_{2}(2,140)=5.11, p<.01\right]$, but not by subjects $\left[F_{1}(2,94)=\right.$ $2.83, p>.05]$. No other interaction with frequency was significant (all $F_{\mathrm{S}}<1$ ).
Table $2 A$

Mean Naming Latencies ( $L$, in Milliseconds) and Error Rate (ER, in \%), With the Corresponding Standard Deviations by Subjects and by Items for the Rhyming Primes of Experiment 2

\begin{tabular}{|c|c|c|c|c|c|c|}
\hline & \multicolumn{2}{|c|}{ NOSE-nose } & \multicolumn{2}{|c|}{ HOSE-nose } & \multicolumn{2}{|c|}{ Rows-nose } \\
\hline & $\mathrm{L}$ & ER & $\mathrm{L}$ & ER & $\mathbf{L}$ & ER \\
\hline \multicolumn{7}{|c|}{ Sublist A } \\
\hline$M$ & 524 & 2.78 & 551 & 2.78 & 557 & 2.78 \\
\hline \multicolumn{7}{|l|}{$S D$} \\
\hline By subjects & 50 & 7.16 & 51 & 7.16 & 49 & 6.28 \\
\hline By items & .30 & 5.50 & 37 & 6.95 & 38 & 6.48 \\
\hline \multicolumn{7}{|c|}{ Sublist B } \\
\hline$M$ & 521 & 4.17 & 565 & 4.17 & 567 & 5.56 \\
\hline \multicolumn{7}{|l|}{$S D$} \\
\hline By subjects & 51 & 8.06 & 51 & 8.77 & 51 & 9.31 \\
\hline By items & 36 & 7.32 & 39 & 7.63 & 40 & 8.57 \\
\hline
\end{tabular}

Table 2B

Mean Naming Latencies ( $L$, in Milliseconds) and Error Rate (ER, in \%), With the Corresponding Standard Deviations by Subjects and by Items for the Control Primes of Experiment 2

\begin{tabular}{|c|c|c|c|c|c|c|}
\hline & \multicolumn{2}{|c|}{ DUTY-nose } & \multicolumn{2}{|c|}{ CHEF-nose } & \multicolumn{2}{|c|}{ DISH-nose } \\
\hline & $\mathrm{L}$ & ER & $\mathrm{L}$ & ER & $\mathrm{L}$ & ER \\
\hline \multicolumn{7}{|c|}{ Sublist A } \\
\hline$M$ & 550 & 0.00 & 548 & 1.04 & 542 & 2.43 \\
\hline \multicolumn{7}{|l|}{$S D$} \\
\hline By subjects & 56 & 0.00 & 46 & 4.08 & 47 & 6.87 \\
\hline By items & 34 & 5.84 & 28 & 3.44 & 37 & 6.31 \\
\hline \multicolumn{7}{|c|}{ Sublist B } \\
\hline$M$ & 552 & 1.39 & 554 & 2.78 & 560 & 1.39 \\
\hline \multicolumn{7}{|l|}{$S D$} \\
\hline By subjects & 51 & 4.66 & 46 & 7.16 & 53 & 4.66 \\
\hline By items & 35 & 4.18 & 37 & 5.34 & 39 & 4.18 \\
\hline
\end{tabular}

The data relevant to the planned comparisons are displayed in Tables 2A-2B and Figure 2. Statistically, NOSEnose differed from DUTY-nose by $29 \mathrm{msec}$, which was highly significant $\left[F_{1}(1,47)=60.74, p<.001 ; F_{2}(1,70)=\right.$ $54.35, p<.001]$; HOSE-nose was slower than CHEF-nose by $8 \mathrm{msec}$, which was significant $\left[F_{1}(1,47)=3.78, p<\right.$ $\left..05 ; F_{2}(1,70)=6.17, p<.05\right]$; similarly, Rows-nose was slower than DISH-nose by $11 \mathrm{msec}$, which was significant $\left[F_{1}(1,47)=11.84, p<.001 ; F_{2}(1,70)=12.56, p<\right.$ $.001]$.

The partial interaction between NOSE-nose versus DUTY-nose (29-msec difference) and HOSE-nose versus CHEF-nose $\left(-8\right.$-msec difference) was significant $\left[F_{1}(1,47)\right.$ $\left.=75.31, p<.001 ; F_{2}(1,70)=43.53, p<.001\right]$. Similarly, the partial interaction between NOSE-nose versus DUTY-nose (29-msec difference) and ROWS-nose versus DisH-nose $(-11-\mathrm{msec}$ difference) was significant $\left[F_{1}(1,47)=43.92, p<.001 ; F_{2}(1,70)=63.35, p<.001\right]$. In contrast, the partial interaction between HOSE-nose versus CHEF-nose ( -8 -msec difference) and Rows nose versus DISH-nose ( -11 -msec difference) was insignificant (both $F \mathbf{S}<1$ ). Because visually similar and dissimi- 


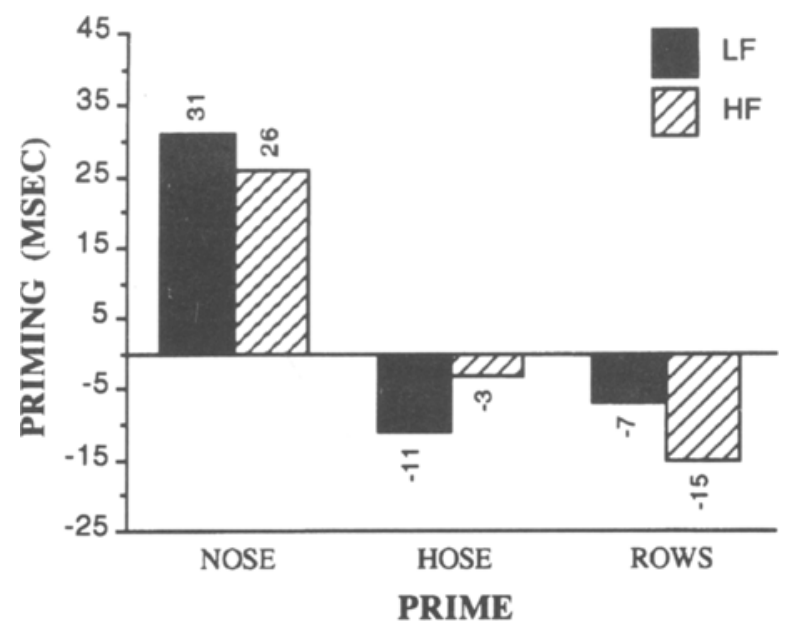

Figure 2. Priming of nose as a function of type of prime and target frequency in Experiment 2.

lar rhyming pairs and their controls did not interact, it was appropriate to collapse the data across both rhyming pairs versus both control pairs. This contrast, with longer latencies for the rhyming pairs, was significant $\left[F_{1}(1,47)=\right.$ $\left.25.21, p<.001 ; F_{2}(1,70)=18.43, p<.001\right]$.

As has been noted, the omnibus ANOVA suggested an interaction between prime type and target frequency. This interaction was entirely due to the difference between identity primes and rhyme primes; it was insignificant when restricted to graphemically similar and graphemically dissimilar rhyming primes (both $F$ s $<1$ ). Nonetheless, the pattern of mean priming effects in Figure 2 suggests the need to test for local word-frequency effects. If we consider the HF stimuli, the partial interaction between HOSE-nose versus CHEF-nose ( -3 -msec difference) and ROWS-nose versus DISH-nose ( -15 -msec difference) was significant $\left[F_{1}(1,47)=4.46, p<.05 ; F_{2}(1,35)=4.19\right.$, $p<.05]$, with the -15 -msec difference between Rows nose versus DISH-nose significant $\left[F_{1}(1,47)=18.02\right.$, $\left.p<.001 ; F_{2}(1,35)=14.65, p<.001\right]$ and the -3 -msec difference between HOSE-nose versus CHEF-nose insignificant (both $F \mathrm{~s}<1$ ). In contrast, if we consider the LF stimuli, the partial interaction between HOSE-nose versus CHEF-nose ( -11 -msec difference) and Rowsnose versus DISH nose $(-8-\mathrm{msec}$ difference) was insignificant (both $F \mathrm{~s}<1$ ). Hence, it was appropriate to collapse the LF data across both rhyming pairs and across both control pairs. The obtained difference $(-10 \mathrm{msec})$ was significant $\left[F_{1}(1,47)=10.28, p<.002 ; F_{2}(1,35)=\right.$ $8.34, p<.01]$.

In the omnibus error analysis, the main effect of rhyme (mean of NOSE-, HOSE-, ROWS- pairs $=3.70 \%$ vs. mean of DUTY-, CHEF-, DISH- pairs $=1.50 \%$ ) was significant $\left[F_{1}(1,47)=10.30, p<.01 ; F_{2}(1,70)=12.17, p<.001\right]$. Other main effects and all interactions in the omnibus error analysis were insignificant (most $F \mathrm{~s}<1$ ). Turning to the planned comparisons on the error data: the $2.08 \%$ difference between NOSE-nose and DUTY-nose was sig- nificant $\left[F_{1}(1,47)=6.71, p<.01 ; F_{2}(1,70)=8.67, p<\right.$ .01 ] , as was the $2.26 \%$ difference between Rows-nose and DISH-nose by $2.26 \%\left[F_{1}(1,47)=5.26, p<.05\right.$; $\left.F_{2}(1,70)=3.98, p<.05\right]$. The $1.56 \%$ difference between HOSE-nose and CHEF-nose was not significant $\left[F_{1}(1,47)=\right.$ $\left.2.38, p>.05 ; F_{2}(1,70)=2.51, p>.05\right]$.

\section{EXPERIMENT 3}

The major outcome of Experiment 2 was the same as that of Experiment 1: Graphemically similar and graphemically dissimilar rhymes exerted an inhibitory influence. Despite the addition of $34 \mathrm{msec}$ to the SOA $(\mathrm{SOA}=36 \mathrm{msec}$ in Experiment $1 \mathrm{vs} . \mathrm{SOA}=70 \mathrm{msec}$ in Experiment 2), and despite the consequent change from unidentifiable to identifiable primes, ${ }^{2}$ inhibition prevailed in Experiment 2 as it had done in Experiment 1 independently of orthographic similarity. The two experiments may have differed, however, in respect to the influence of target frequency. In Experiment 2, in contrast with Experiment 1, target frequency and graphemic similarity of the prime interacted. Although the form of the interaction cannot be readily interpreted, the fact that it was observed at the longer SOA of $70 \mathrm{msec}$ is consistent with the idea that the conditions giving rise to inhibition become less pronounced with time, allowing other influences on word naming to become manifest. In Experiment 3 , the SOA was extended even further, to $250 \mathrm{msec}$, under the assumption that the inhibition due to partial overlap would be dissipated at this time scale. Presumably, the phonological code for the prime should be fully established by $250 \mathrm{msec}$ prior to the target's occurrence. If inhibition arises only when partially overlapping phonological codes are moving toward coherence simultaneously, it should be absent when sufficient time is allowed for one code to be fully stabilized before the other starts to form.

Experiment 3 differed from Experiments 1 and 2 in a further way. Identity primes (and their controls) were replaced by nonword rhymes (and their controls). Because identity priming is well established at long intervals, it was considered that an examination of nonword rhyme priming would be more useful. In other research, involving long SOAs and Serbo-Croatian materials, nonword rhymes produced the same effect as did word rhymes (Lukatela, Carello, \& Turvey, 1990; Lukatela \& Turvey, 1990). A similar outcome might be expected for English language materials.

\section{Method}

Subjects. Fourty-eight undergraduates at the University of Connecticut served as subjects in Experiment 3. None had participated in Experiments 1 and 2. A subject was assigned to one of six groups, according to the time he/she arrived at the laboratory, to give a total of 8 subjects per group.

Materials. The stimuli were the same as in Experiments 1 and 2, except that List 1 and List 4 were reconstructed. In List 1 the identity related prime-target pairs (e.g., SUN-sun, MOLE-sun) were replaced by nonword-word rhyming pairs (e.g., LuN-sun, 
YOLE-mole). In most cases, the pseudorhyme and the corresponding target word differed in the initial letter or letters. As in the example of VOZE (in VOZE-nose), however, it is evident that differences had to occur elsewhere in the letter string in order to guarantee an unambiguous pseudorhyme. In List 4 , all control word primes were replaced by nonrhyming nonwords (e.g,, THEG as the control for VOZE).

Procedure. The procedure was the same as in Experiment 1, with the exception of the stimulus sequence: a visual mask for $500 \mathrm{msec}$, the prime for $125 \mathrm{msec}$, another visual mask for $125 \mathrm{msec}$, and the target for $400 \mathrm{msec}$. The stimuli followed each other at an ISI $=0 \mathrm{msec}$. Consequently, the SOA was $250 \mathrm{msec}$.

\section{Results}

In the debriefing, all subjects reported an ability to see the priming word in the "complex" visual mask that preceded the to-be-named target word. The $3 \times 2 \times 2$ (prime type $\times$ rhyme $\times$ target frequency) omnibus ANOVA described in Experiment 1 was conducted on naming latencies. There was no main effect of target frequency $(\mathrm{HF}=545 \mathrm{msec}$ vs. $\mathrm{LF}=553 \mathrm{msec})\left[F_{1}(1,47)=\right.$ $\left.3.82, p>.05 ; F_{2}(1,70)=1.17, p>.05\right]$, and there were no interactions with frequency (all $F_{\mathrm{S}}<1$ ).

The data relevant to the planned comparisons are displayed in Tables 3A-3B and Figure 3. VozE-nose was faster

Table 3A

Mean Naming Latencies ( $L$, in Milliseconds) and Error Rate (ER, in \%), With the Corresponding Standard Deviations by Subjects and by Items for the Rhyming Primes of Experiment 3

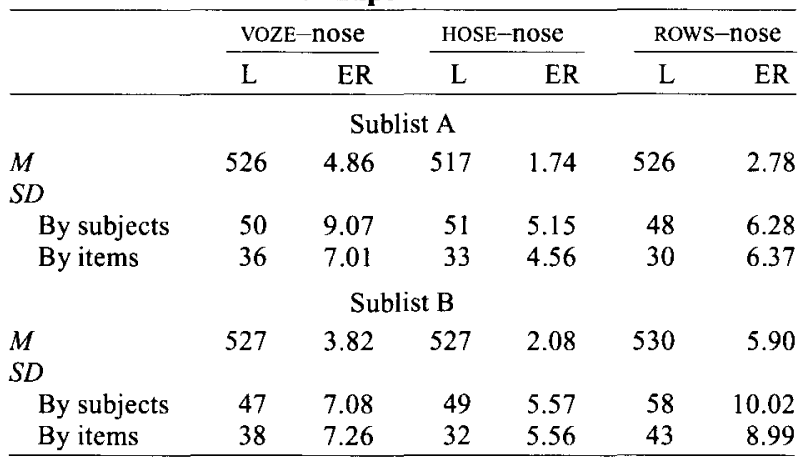

Table 3B

Mean Naming Latencies ( $L$, in Milliseconds) and Error Rate (ER, in \%), With the Corresponding Standard Deviations by Subjects and by Items for the Control Primes of Experiment 3

\begin{tabular}{|c|c|c|c|c|c|c|}
\hline & \multicolumn{2}{|c|}{ THEG-nose } & \multicolumn{2}{|c|}{ CHEF-nose } & \multicolumn{2}{|c|}{ DISH-nose } \\
\hline & $\mathrm{L}$ & ER & $\mathrm{L}$ & ER & $\mathrm{L}$ & ER \\
\hline \multicolumn{7}{|c|}{ Sublist A } \\
\hline $\begin{array}{l}M \\
S D\end{array}$ & 529 & 1.74 & 526 & 1.39 & 526 & 1.39 \\
\hline By subjects & 53 & 5.15 & 57 & 4.66 & 48 & 4.66 \\
\hline By items & 36 & 5.34 & 37 & 5.40 & 30 & 3.93 \\
\hline \multicolumn{7}{|c|}{ Sublist B } \\
\hline $\begin{array}{l}M \\
S D\end{array}$ & 526 & 2.08 & 531 & 2.43 & 530 & 1.39 \\
\hline By subjects & 46 & 5.57 & 52 & 5.94 & 58 & 4.66 \\
\hline By items & 32 & 6.38 & 37 & 4.90 & 43 & 4.03 \\
\hline
\end{tabular}

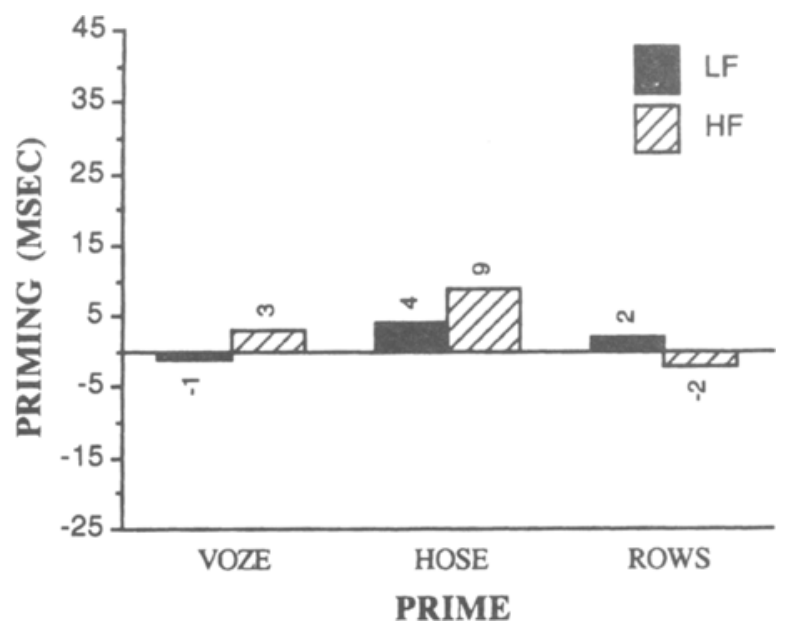

Figure 3. Priming of nose as a function of type of prime and target frequency in Experiment 3.

than THEG-nose by $1 \mathrm{msec}\left(F_{1}<1 ; F_{2}<1\right)$, and HOSEnose was faster than CHEF-nose by $6 \mathrm{msec}\left[F_{1}(1,47)=\right.$ $\left.4.13, p<.05 ; F_{2}(1,70)=1.78, p>.05\right]$. Rows-nose was equal to DISH-nose. All partial interactions (including those involving frequency) were insignificant $(F \mathrm{~s}<1)$.

In the omnibus error analysis, the main effect of rhyme (mean of VOZE - , HOSE - , ROWS- pairs $=3.53 \%$ vs. mean of THEG-, CHEF-, DISH- pairs $=1.74 \%$ ) was significant $\left[F_{1}(1,47)=10.34, p<.01 ; F_{2}(1,70)=10.98\right.$, $p<.001]$. Other main effects and all interactions in the omnibus error analysis were insignificant (most $F_{\mathbf{s}}<1$ ). In the planned comparisons on the error data, the $-2.43 \%$ difference between VOZE-nose and THEG-nose was significant $\left[F_{1}(1,47)=6.01, p<.05 ; F_{2}(1,70)=\right.$ $6.35, p<.05]$, as was the $-2.95 \%$ difference between Rows-nose and DISH-nose $\left[F_{1}(1,47)=5.26, p<.05\right.$; $\left.F_{2}(1,70)=3.98, p<.05\right]$. In contrast, the errors made to HOSE-nose equalled those made to CHEF-nose. The $-2.95 \%$ difference between Rows-nose and DISH-nose was significantly different than the $0 \%$ difference between HOSE-nose and CHEF-nose $\left[F_{1}(1,47)=6.58, p<\right.$ $\left..05 ; F_{2}(1,70)=5.56, p<.05\right]$.

\section{GENERAL DISCUSSION}

Together, Experiments 1 and 2 suggest that the activity engendered by a rhyme prime is (1) initially and primarily phonological, and (2) competitive with the activity engendered by its target. Unlike a homophonic prime that would produce an activation pattern among phonological subsymbols identical to that of its target, a rhyme prime would produce an activation pattern that overlapped only in part. Apparently, this partial overlap at the short time scales of Experiments 1 and 2 is more of a hindrance than a help. The successful demonstration of an inhibitory rhyming effect on naming English words in Experiments 1 and 2 counters the failure to find any 
effect by Peter et al. (1990). It also contrasts with the varied results (null, inhibitory, facilitatory) found in the experiments by Lupker and Colombo (1994) and the understanding expressed by these investigators that inhibition is limited to clearly visible primes and high-frequency targets. The SOA exceeded $500 \mathrm{msec}$ in the Peter et al. study and $140 \mathrm{msec}$ in the experiments of Lupker and Colombo. The contrast between the results of the present Experiment $3(\mathrm{SOA}=250 \mathrm{msec})$ and those of the present Experiments 1 and 2 (SOAs of 36 and $70 \mathrm{msec}$, respectively) strongly suggests that assessments of putative dimensions of priming cannot be made on the basis of long SOAs. The requisite studies must be parametric and must include brief SOAs $(0 \mathrm{msec}<\mathrm{SOA}<100 \mathrm{msec})$ (e.g., Ferrand \& Grainger, 1992; Lukatela \& Turvey, 1994a, 1994b). In the context of these remarks, the unsuccessful investigations of Peter et al. may be reconsiderd in the light of the limited effects observed in Experiment 3 relative to Experiments 1 and 2. Apparently, rhyme priming of naming moves toward null effects as SOA increases. Similarly, the varied outcomes observed by Lupker and Colombo may be interpreted as indicating that rhyme priming of naming depends on both SOA and the orthographic-phonological consistency of the prime and target.

It is especially noteworthy that the equal inhibitory effects of HOSE and ROWS on nose occurred in Experiment 1 with a prime-target SOA of $36 \mathrm{msec}$ and a prime-mask SOA (and, therefore, pure prime duration) of $18 \mathrm{msec}$. This result counters the experimental results of Ferrand and Grainger (1992), obtained with the lexical decision task, suggesting that phonological codes for primes may not be available at prime durations/SOAs less than $60 \mathrm{msec}$. (More direct comparisons between the present results and those of Ferrand and Grainger [1992, 1993, 1994] are ruled out, however, by the observations that phonological and rhyme priming are very different and that rhyme priming in naming and lexical decision are very different [Lukatela et al., 1990; Lukatela \& Turvey, 1990].) Another noteworthy aspect of the present data is the implication that although orthographically similar rhymes are indistinguishable from orthographically dissimilar rhymes in their effects on naming at SOAs $\leq$ $70 \mathrm{msec}$ (Experiments 1 and 2), they may become distinct at SOAs $\geq 250 \mathrm{msec}$ (Experiment 3 ). In the error analysis of Experiment 3, the contrast between HOSEnose and CHEF-nose was significantly different from that between ROWS-nose and DISH-nose. An absence of significant orthographic effects at very short time scales and an emergence of such effects at long time scales would be consistent with the view (within the phonological coherence hypothesis) that the role of orthographic codes is primarily that of a subsequent "cleaning up" or refining of the representations activated initially by phonology (Lukatela \& Turvey, 1994a, 1994b; Van Orden \& Goldinger, 1994).

According to the phonological coherence hypothesis, a naming response is specified when visual and phono- logical subsymbols cohere in resonance (Van Orden \& Goldinger, 1994). The data suggest that the time evolution of this coherence in the case of the target nose is retarded more by HOSE and ROWS than by their controls CHEF and DISH, respectively. It was remarked in the introduction that the resonances within the phonologicalsemantic network arising from processing HOSE and Rows might impede the processing of nose. That is, we conjectured that reinforcement of the phonological code /hoz/ or /roz/ through the phonological-semantic network could oppose the establishment of the requisite phonological code /noz/. A key role in generating inhibitory rhyming effects would similarly be assigned to the lexical level in Ferrand and Grainger's (1992, 1994) account of orthographic and phonological priming. They propose a modified version of the McClelland and Rumelhart's (1981) interactive model, in which sublexical orthographic units connect to both sublexical phonological units and lexical units but the phonological units connect only to the lexical units. On presentation of a word, activity builds up in the orthographic units leading to both phonological and lexical activity. Orthographic and phonological activity induced by HOSE, for example, causes activity in the lexical representations hose and nose (and others that share the same orthographic and phonological subpatterns). As the lexical activity grows, however, intralexical inhibition develops, with the consequence that the faster growing hose opposes the preactivation of nose. Consequently, when the target nose is presented, activity in its lexical representation grows more slowly than it would otherwise, and more time is needed to access lexical information about how "nose" is pronounced. It should be apparent that predicted facilitation and inhibitory effects in the Ferrand and Grainger account depend on the phasing of orthographic and phonological activation of the lexicon relative to the growth of intralexical inhibition.

If we return to the resonance idea, a closely related and potentially important way of understanding the inhibitory nature of rhyme interaction is through the notion of componential attractors (Plaut, McClelland, Seidenberg, \& Patterson, 1996). In an attractor network, in which attractors are identified with computational objects (e.g., familiar, nameable entities), the pattern of activity initially defined over a set of units lies within one or more basins of attraction. Over time, the pattern evolves through mutual interactions among the units, toward the nearest attractor pattern. This settling process is a "clean-up process"; initial encodings that are at some remove from the attractor eventually converge on the attractor. With the network conceived as a multidimensional state space, the activity of each unit represents the state of a separate dimension with the instantaneous pattern of activity over all units corresponding to a single point in the space. The time evolution of this point is toward the attractor. As commonly applied (see, e.g., Hinton \& Sejnowski, 1986; Hinton \& Shallice, 1991), the notion of an attractor seems ill-suited to the mapping 
from orthography to phonology (Plaut et al., 1996). If the network develops attractors for word pronunciations, then a novel input, a nonword, would fall within the basin of attraction of a similar word, giving rise to a familiar rather than novel output. To circumvent this problem, it is suggested that the network develops attractors for words that are componential (Van Orden \& Goldinger, 1994), consisting of substructures that reflect common sublexical correspondencies between orthography and phonology - for example, the onset, vowel, and coda correspondencies (Plaut et al., 1996). The attractor basins for (regular) words then consist of three, separate, orthogonal sub-basins. On presentation of a word, a network so designed will settle into a region of state space where these sub-basins overlap, corresponding to the word's name. The sub-basins can apply independently, however, so that spurious attractor basins exist where the sub-basins for word segments overlap (Plaut et al., 1996). Such overlaps specify pronounceable nonwords that would be adequately named, given the appropriate orthographic input.

With respect to the present data, the orthographicphonological network responds to the prime HOSE or the prime Rows by settling into (when SOA is long), or moving in the direction of (when SOA is brief), two of the three sub-attractors (specifically, the vowel and the coda) to which the network will be drawn when the target nose is presented. In contrast, for the control primes CHEF and DISH, there are no componential attractors shared with the target. Achieving a pronunciation of the target nose following either HOSE or ROwS at a very brief SOA requires that the network must stay within two of the currently busy sub-basins and exit from one of them. Paraphrasing the conclusion from above, the present data suggest that at short SOAs a partial overlap of componential attractors between prime and target slows the emergence of the pattern supporting the pronunciation of the target. In contrast, when the overlap is perfect (NOSEnose), emergence of the appropriate pattern is accelerated, and when the overlap is null (CHEF-nose, DISHnose), emergence is slowed less or simply unaffected.

Finally, we consider a potentially very different interpretation of the present data that follows from the onset effect reported by Forster and Davis (1991). They found in a naming task with masked primes that rhyming pairs such as take-BREAK did not differ from their control pairs (merry-BREAK) but nonrhyming pairs with identical onsets such as belly-BREAK did differ from the controls in the direction of faster naming of the target. Forster and Davis conjectured that a Stroop-like interference effect was produced in take-BREAK pairs by competing tendencies to pronounce both the prime and the target. By the same token, a common initial pronunciation as in belly-BREAK produces Stroop-like facilitation. The primary lesson of these observations for masked priming effects on naming is that onset identity is more important than overall phonological similarity. Accordingly, the results of Experiments 1 and 2 could be interpreted as manifestations of this Stroop-like interference arising from onset differences rather than phonological similarity. Against such an interpretation, however, are a large number of experimental results that contradict the onset effect in conditions similar to and conditions identical to those of the present experiments. In their investigations of phonological priming at brief SOAs, Lukatela and Turvey (1994b) found that whereas TOAD (in lowercase) was named faster following TOWED rather than PLASM (the matched control for TOWED), the naming of TOAD following TOLD was no faster than the naming of TOAD following GAVE (the matched control for TOLD). Similarly, priming of TOAD by the nonword TODE (relative to the control LAIM-TOAD) was more reliable than priming of TOAD by the nonword TODS (relative to the control LARMTOAD) at brief SOAs. If onset identity and not phonological similarity mattered, then TOLD and TODS (same onsets as that of TOAD) should have been as different from GAVE and LARM (different onsets than that of TOAD), respectively, as TOWED and TODE were different from PLASM and LAIM, respectively. Relatedly, in experiments on associative priming by proper associates, homophones, and pseudohomophones, Lukatela and Turvey (1994a) found reliable priming of FROG at very brief SOAs by TOWED and TODE but not by TOLD and TORD. In associative and pseudoassociative priming over short time scales as in phonological priming over short time scales, phonological similarity rather than onset identity is clearly the crucial variable.

In sum, the present research has shown a robust rhyme priming effect that stands in contrast to the ambiguous pattern of results found in the literature. The contrast between Experiment 3 and Experiments 1 and 2 suggests that the ambiguity of past research is largely due to an inappropriate choice of time scales (SOAs) over which to view the interaction of visually presented rhymes or to inappropriate controls or (as seems more likely) to both factors. The fact that the observed rhyme interaction in Experiments 1 and 2 retarded target naming in contrast to the facilitation that is observed for homophone interaction at the same time scales points in the direction of componential attractors governing processes in the orthography-to-phonology mapping (Plaut et al., 1996; Van Orden \& Goldinger, 1994). And the fact that the priming effect was the same in magnitude and direction for orthographically similar and dissimilar rhymes provides further encouragement for accounts of word processing in which phonological codes, rather than orthographic codes, play the leading role (Lukatela \& Turvey, 1994a, 1994b; Van Orden \& Goldinger, 1994; Van Orden et al., 1990).

\section{REFERENCES}

BowEY, J. A. (1993). Orthographic rime priming. Quarterly Journal of Experimental Psychology, 46A, 247-271.

DAvIS, C., \& ForSTER, K. I. (1994). Masked orthographic priming: The effect of prime-target legibility. Quarterly Journal of Experimental Psychology, 47A, 673-697.

Ferrand, L., \& Grainger, J. (1992). Phonology and orthography in visual word recognition: Evidence from masked nonword priming. Quarterly Journal of Experimental Psychology, 45A, 353-372. 
Ferrand, L., \& Grainger, J. (1993). The time course of orthographic and phonological code activation in the early phases of visual word recognition. Bulletin of the Psychonomic Society, 31, 119-122.

FERRAND, L., \& GRAINGER, J. (1994). Effects of orthography are independent of phonology in masked form priming. Quarterly Journal of Experimental Psychology, 47A, 365-382.

FORSTER, K. I. (1987). Form priming with masked primes: The best match hypothesis. In M. Coltheart (Ed.), Attention and performance $X I I$ (pp. 127-146). Hillsdale, NJ: Erlbaum.

Forster, K. I., \& DAVIS, C. (1991). The density constraint on formpriming in the naming task: Interference effects from a masked prime. Journal of Memory \& Language, 30, 1-25.

Grossberg, S. (1980). How does a brain build a cognitive code? Psychological Review, 87, 1-51.

Hillinger, M. L. (1980). Priming effects with phonemically similar words: The encoding-bias hypothesis reconsidered. Memory \& Cognition, 8, 115-123.

HINTON, G. E., \& SEJNOWSKI, T. J. (1986). Learning and relearning in Boltzman machines. In D. E. Rumelhart, J. L. McClelland, \& the PDP research group (Eds.), Parallel distributed processing: Explorations in the microstructure of cognition: Vol. 1. Foundations (pp. 282-317). Cambridge, MA: MIT Press.

Hinton, G. E., \& Shallice, T. (1991). Lesioning an attractor network: Investigations of acquired dyslexia. Psychological Review, 98, 74 95 .

Humphreys, G. W., Besner, D., \& Quinlan, P. T. (1988). Event perception and the word repetition effect. Journal of Experimental Psychology: General, 117, 51-67.

Lukatela, G., Carello, C., \& Turvey, M. T. (1990). Phonemic priming by words and pseudowords. European Journal of Cognitive Psychology, 2, 375-394.

Lukatela, G., \& Turvey, M. T. (1990). Phonemic similarity effects and prelexical phonology. Memory \& Cognition, 18, 128-152.

Lukatela, G., \& Turvey, M. T. (1994a). Visual lexical access is injtially phonological: 1 . Evidence from associative priming by words, homophones, and pseudohomophones. Journal of Experimental Psychology: General, 123, 107-128.

Lukatela, G., \& Turvey, M. T. (1994b). Visual lexical access is initially phonological: 2 . Evidence from phonological priming by homophones and pseudohomophones. Journal of Experimental Psychology: General, 123, 331-353.

LUPKER, S. J., \& COLOMBO, L. (1994). Inhibitory effects in form priming: Evaluating a phonological competition explanation. Journal of Experimental Psychology: Human Perception \& Performance, 20, 437-451.

Martin, R. C., \& Jensen, C. R. (1988). Phonological priming in the lexical decision task: A failure to replicate. Memory \& Cognition, 16, 505-521.

MCClelland, J. L., \& Rumelhart, D. E. (1981). An interactive activation model of context effects in letter perception: Part 1. An account of basic findings. Psychological Review, 88, 375-407.

Meyer, D. E., Schvaneveldt, R. W., \& Ruddy, M. G. (1974). Functions of graphemic and phonemic codes in visual word-recognition. Memory \& Cognition, 2, 309-321.

Michaels, C. F., \& Turvey, M. T. (1979). Central sources of visual masking: Indexing structures supporting seeing at a single, brief glance. Psychological Research, 41, 1-61.

O'Seaghdha, P. G., Dell, G. S., Peterson, R. R., \& Juliano, C. (1992). Modelling form-related priming in comprehension and production. In R. G. Reilly \& N. E. Sharkey (Eds.), Connectionist approaches to natural language understanding (pp. 373-408). Hillsdale, NJ: Erlbaum.

Perfetti, C. A., Zhang, S., \& Berent, I. (1992). Reading in English and Chinese: Evidence for a "universal" phonological principle. In R. Frost \& L. Katz (Eds.), Orthography, phonology, morphology, and meaning (pp. 227-248). Amsterdam: Elsevier, North-Holland.

Peter, M., Lukatela, G., \& Turvey, M. T. (1990). Phonological priming: Failure to replicate in the rapid naming task. Bulletin of the Psychonomic Society, 28, 389-392.

Plaut, D. C., McClelland, J. L., Seidenberg, M. S., \& Patterson, K. E. (1996). Understanding normal and impaired word reading:
Computational principles in quasi-regular domains. Psychological Review, 103, 56-115.

TURVEY, M. T. (1973). On peripheral and central processes in vision: Inferences from an information-processing analysis of masking with patterned stimuli. Psychological Review, 80, 1-52.

TURVEY, M. T. (1978). Visual processing and short-term memory. In W. K. Estes (Ed.), Handbook of learning and cognitive processes (Vol. 5, pp. 91-140). Hillsdale, NJ: Erlbaum.

VAN ORDEN, G. C. (1987). A ROWS is a ROSE: Spelling, sound, and reading. Memory \& Cognition, 15, 181-198.

VAN ORDEN, G. C., \& Goldinger, S. D. (1994). The interdependence of form and function in cognitive systems explains perception of printed words. Journal of Experimental Psychology: Human Perception \& Performance, 20, 1269-1291.

Van Orden, G. C., Pennington, B. F., \& Stone, G. O. (1990). Word identification in reading and the promise of subsymbolic psycholinguistics. Psychological Review, 97, 488-522.

\section{NOTES}

1. In support of this idea, Lukatela and Turvey (1994b) observed differences between two experiments on TODE-toad priming at a prime-target SOA of $60 \mathrm{msec}$ - one of which used an intervening pattern mask of 30-msec duration (Experiment 6), and one of which did not (Experiment 4). With the intervening pattern mask, the prime became identifiable, pseudohomophonic priming became reliable, and overall naming errors and times were reduced. The recovery of a previously masked stimulus with the addition of further stimuli is characteristic of masking procedures that use several stimuli, so-called $n$ field masking (Michaels \& Turvey, 1979; Turvey, 1978). The contrast observed by Lukatela and Turvey (1994b) implies that, at a very short SOA, the experimental capability of revealing phonological influences of a brief prime on the processing of a prolonged target (they used a 400 -msec target duration) is enhanced by an inserted mask because it lessens the possibility that the specific orthographic processing units encoding the prime are still active during the encoding of the target. In short, the possibility that the benefits of orthographic commonalities will obscure the benefits of phonological commonalities is reduced.

Recently, Davis and Forster (1994) reported effects potentially attributable to orthographic persistence when prime and target were equally brief (e.g., both $40 \mathrm{msec}$ ), but not when they differed markedly in duration (prime $=60 \mathrm{msec}$, target $=500 \mathrm{msec}$ ). Specifically, they used primes and targets which, when superimposed, yielded either legible or illegible targets and found this manipulation to be insignificant when targets were prolonged and the response measure was either identification or lexical decision. It is well known, however, that for binocular presentation of stimuli at brief SOAs, the perceptibility of a lagging more energetic stimulus (a 500 -msec target) will be largely immune to the leading less energetic stimulus (a $60-\mathrm{msec}$ prime) (see, e.g., Turvey, 1973). Such an effect should not be interpreted to mean, however, that any featural/orthographic activity initiated by the leading stimulus failed to persist beyond the onset of the lagging stimulus. A further aspect of the Davis and Forster study that recommends caution in interpreting their results is that parametric manipulations of SOA reveal a nonlinear dependency of perception on SOA with different variables (e.g., monocular/binocular vs. dichoptic viewing, nonword vs. word) exerting their influences at different phases of the function - that is, at different ranges of SOA $\leq$ $250 \mathrm{msec}$ (see Michaels \& Turvey, 1979). Any failure to find an effect at any one arbitrarily chosen SOA cannot be taken as evidence that the effect does not occur.

2. The identifiability of primes does not seem to be important to the kinds of phonological effects observed under the present conditions of stimulus presentation. In the experiments of Lukatela and Turvey (1994a, 1994b), on which the present experiments are based, associative and phonological priming at brief SOAs were found with both identifiable and unidentifiable primes. The present experiments suggest a similar independence of priming effects from identifiability. There are, however, a number of suggestions that identifiability is a key feature determining the presence or absence of priming effects 
(e.g., Forster, 1987) and, perhaps, the form of priming (inhibitory or facilitatory) (e.g., Lupker \& Colombo, 1994). Further examination of this issue is obviously required.

\section{APPENDIX A Stimulus Materials in Experiments 1 and 2}

Each row identifies, in order, the target (which is also the identity prime), the graphemically similar prime, the graphemically dissimilar prime, and their respective controls.
1. BEAR, PEAR, HAIR, SPOT, COMB, CLUB
2. BEAT, MEAT, SWEET, LIPS, IRON, APRIL
3. BLOCK, FROCK, WALK, OUGHT, SPURT, CLAY
4. BREAK, STEAK, RAKE, CARRY, CIGAR, POPS
5. CANE, MANE, VEIN, PLOW, HORD, STAR
6. COAT, OAT, QUOTE, MAMA, ICH, BUNCH
7. COPE, HOPE, SOAP, FANS, LIVE, GANG
8. CREAM, DREAM, SEEM, SLIDE, EMPTY, COST

9. CREW, BLEW, BLUE, FISH, SNAP, OBEY

10. CRIES, FLIES, GUYS, STAIN, HARSH, SLIM

11. CURE, PURE, TOUR, FLED, SPOT, TEND

12. CURL, HURL, GIRL, SHAH, BEAN, ABLE

13. DONE, NONE, SPUN, AREA, STAY, KICK

14. DUMB, NUMB, SOME, TIPS, RAFT, ONLY

15. FAIR, PAIR, CARE, VOTE, HOLY, SORT

16. FATE, HATE, BAIT, KIDS, LOTS, SNUG

17. FEAR, DEAR, BEER, NOTE, HUGE, DAMN

18. FIRST, THIRST, WORST, OTHER, ADHERE, CRAZY

19. FLOOD, BLOOD, STUD, DRANK, MARCH, EXIT

20. FOOD, MOOD, CRUDE, REST, NAVY, HATS

21. GALE, BALE, MAIL, YOGI, CHAP, SKIN

22. GOAL, COAL, POLL, TASK, CURT, FLIP

23. GREET, BEET, EAT, FATTY, FEUD, WON

24. HEAD, DEAD, SHED, CITY, ELSE, DUKE

25. HEEL, PEEL, DEAL, CAGE, FLOC, WHOM

26. HOME, DOME, ROAM, WENT, CHIP, SLIT

27. HORN, SCORN, WARN, CUTS, APTLY, RIBS

28. HOUR, SOUR, TOWER, BILL, FLOC, WIRES

29. LACKS, TACKS, AXE, BEECH, BUNNY, RUB

30. LEARN, YEARN, TURN, AWARE, ELEGY, WIFE

31. LIGHT, MIGHT, QUITE, POWER, WHILE, DEATH

32. LOAN, MOAN, TONE, SALT, WADS, EDGE

33. LOW, TOW, DOE, PAY, RAY, GAL

34. MATE, LATE, EIGHT, UGLY, KEPT, SPENT

35. MOLE, HOLE, SOUL, DUMP, BUSY, RING

36. MORE, BORE, FOUR, WILL, DRUG, BEST

37. NAIL, RAIL, PALE, BURY, SINS, USES

38. NIGHT, RIGHT, SITE, OFTEN, SINCE, JOBS

39. NOISE, POISE, BOYS, DRUNK, BURNT, CLUB

40. NOSE, HOSE, ROWS, DUTY, CHEF, DISH

41. NUDE, RUDE, LEWD, BUCK, DISK, DIST

42. PAIN, GAIN, REIN, LOSS, RICH, GILT

43. PEACE, LEASE, GEESE, TRUTH, ORBIT, DUMMY

44. PEEP, DEEP, LEAP, QUIZ, MASS, BUSH

45. POOL, COOL, RULE, CARS, BABY, SEND

46. QUART, WART, PORT, CHESS, ADDS, NUTS

47. QUEEN, SEEN, DEAN, ATOMS, BODY, SELF

48. RAID, PAID, FADE, PONY, HALL, SIRS

49. RATE, SLATE, GAIT, PLAN, FORUM, DOCK

50. REEF, BEEF, BRIEF, BOLT, HORN, TWICE

51. ROAR, BOAR, DOOR, ACID, MALT, HELP

52. ROOT, LOOT, FRUIT, FLUX, GASP, YIELD

53. ROUGH, TOUGH, CUFF, SHIFF, KINDS, DENS

54. SEA, PEA, BEE, ARM, DUN, LOG
55. SHADE, BLADE, MAID, MERIT, VIRUS, RICE

56. SIGH, HIGH, PIE, KEEN, ONCE, WAX

57. SLEEP, STEEP, HEAP, BIRTH, PATCH, AMID

58. SLOW, BLOW, TOE, VAST, VARY, IVY

59. SNOOP, TROOP, SOUP, BASIL, QUEST, LINK

60. SPEAK, FREAK, SEEK, CORPS, ETHOS, LIPS

61. STAFF, CHAFF, GRAPH, GIVES, ANTIC, SHOPS

62. STEAL, SEAL, PEEL, ALTAR, WING, ABLE

63. SUN, BUN, TON, HIT, GAB, OAR

64. TAIL, SAIL, HALE, SLID, TROT, RINK

65. TALE, SALE, VEIL, RENT, TEND, MOCK

66. TALL, FALL, HAUL, HUGE, REST, CRIB

67. THIEF, GRIEF, LEAF, FOCAL, SWEAR, BITS

68. TRAIT, WAIT, DATE, FOYER, LORD, NEWS

69. TYPE, HYPE, PIPE, SAYS, DUCT, CROP

70. WEIGH, NEIGH, HAY, DRYER, AFFIX, LAP

71. WINE, SINE, SIGN, EVEL, FUSS, PARK

72. ZOO, WOO, TRUE, TAN, LAX, COST

\section{APPENDIX B Stimulus Materials in Experiment 3}

Each row identifies, in order, the target, the rhyming nonword prime, the graphemically similar prime, the graphemically dissimilar prime, and their respective controls.

1. BEAR, SNAIR, PEAR, HAIR, KNALL, COMB, CLUB

2. BEAT, LEET, MEAT, SWEET, POUC, IRON, APRIL

3. BLOCK, TROCK, FROCK, WALK, WOONS, SPURT, CLAY

4. BREAK, DAKE, STEAK, RAKE, HOIM, CIGAR, POPS

5. CANE, TANE, MANE, VEIN, NAWG, HORD, STAR

6. COAT, NOAT, OAT, QUOTE, BYRN, ICH, BUNCH

7. COPE, WOPE, HOPE, SOAP, DIRS, LIVE, GANG

8. CREAM, GREEM, DREAM, SEEM, ROUNS, EMPTY, COST

9. CREW, FRUE, BLEW, GLUE, PARN, SNAP, OBEY

10. CRIES, BRIES, FLIES, GUYS, DOLMS, HARSH, SLIM

11. CURE, FURE, PURE, TOUR, ROGS, SPOT, TEND

12. CURL, MURL, HURL, GIRL, KNEP, BEAN, ABLE

13. DONE, GRUN, NONE, SPUN, WATH, STAY, KICK

14. DUMB, LUMB, NUMB, SOME, BALK, RAFT, ONLY

15. FAIR, TAIR, PAIR, CARE, LEPH, HOLY, SORT

16. FATE, JATE, HATE, BAIT, GOUG, LOTS, SNUG

17. FEAR, KEER, DEAR, BEER, SART, HUGE, DAMN

18. FIRST, VIRST, THIRST, WORST, SWALS, ADHERE, CRAZY

19. FLOOD, GLUD, BLOOD, STUD, SECK, MARCH, EXIT

20. FOOD, ZOOD, MOOD, CRUDE, GUNF, NAVY, HATS

21. GALE, LALE, BALE, MAIL, DEMS, CHAP, SKIN

22. GOAL, ZOAL, COAL, POLL, ERST, CURT, FLIP

23. GREET, FREET, BEET, EAT, STONK, FEUD, WON

24. HEAD, KNED, DEAD, SHED, SARF, ELSE, DUKE

25. HEEL, BEEL, PEEL, DEAL, NALM, FLOC, WHOM

26. HOME, YOME, DOME, ROAM, FULP, CHIP, SLIT

27. HORN, SORN, SCORN, WARN, BALK, APTLY, RIBS

28. HOUR, LOUR, SOUR, TOWER, ERMS, FLOC, WIRES

29. LACKS, GACKS, TACKS, AXE, FLART, BUNNY, RUB

30. LEARN, VEARN, YEARN, TURN, DIOPH, ELEGY, WIFE

31. LIGHT, GITE, MIGHT, QUITE, PAUPS, WHILE, DEATH

32. LOAN, DOAN, MOAN, TONE, JALD, WADS, EDGE

33. LOW, POE, TOW, DOE, ARL, RAY, GAL

34. MATE, SATE, LATE, EIGHT, HOPR, KEPT, SPENT

35. MOLE, ZOLE, HOLE, SOUL, TARK, BUSY, RING

36. MORE, VORE, BORE, FOUR, DIEP, DRUG, BEST

37. NAIL, DAIL, RAIL, PALE, HEEN, SINS, USES

38. NIGHT, PITE, RIGHT, SITE, RALM, SINCE, JOBS 
39. NOISE, GOISE, POISE, BOYS, CHENT, BURNT, CLUB

40. NOSE, VOZE, HOSE, ROWS, THEG, CHEF, DISH

41. NUDE, SUDE, RUDE, LEWD, ALKS, DISK, DIST

42. PAIN, TAIN, GAIN, REIN, NIFL, RICH, GILT

43. PEACE, REECE, LEASE, GEESE, VIRTS, ORBIT, DUMMY

44. PEEP, FEEP, DEEP, LEAP, DING, MASS, BUSH

45. POOL, SOOL, COOL, RULE, PLEX, BABY, SEND

46. QUART, MORT, WART, PORT, HEGS, ADDS, NUTS

47. QUEEN, WEEN, SEEN, DEAN, LASK, BODY, SELF

48. RAID, GAID, PAID, FADE, HOYT, HALL, SIRS

49. RATE, NATE, SLATE, GAIT, THYG, FORUM, DOCK

50. REEF, GEEF, BEEF, BRIEF, TOON, HORN, TWICE

51. ROAR, JORE, BOAR, DOOR, GALM, MALT, HELP

52. ROOT, KOOT, LOOT, FRUIT, FULB, GASP, YIELD

53. ROUGH, DUFF, TOUGH, CUFF, SPEM, KINDS, DENS

54. SEA, REE, PEA, BEE, OSP, DUN, LOG

55. SHADE, CHADE, BLADE, MAID, PLEUR, VIRUS, RICE
56. SIGH, MIE, HIGH, PIE, POOK, ONCE, WAX 57. SLEEP, FLEEP, STEEP, HEAP, GRALD, PATCH, AMID 58. SLOW, KLOW, BLOW, TOE, YERT, VARY, IVY 59. SNOOP, FLOOP, TROOP, SOUP, DEITH, QUEST, LINK 60. SPEAK, DEEK, FREAK, SEEK, YONG, ETHOS, LIPS

61. STAFF, BAFF, CHAFF, GRAPH, KNEP, ANTIC, SHOPS 62. STEAL, YEEL, SEAL, PEEL, ROPS, WING, ABLE 63. SUN, YUN, BUN, TON, TEB, GAB, OAR 64. TAIL, LAIL, SAIL, HALE, ROOB, TROT, RINK 65. TALE, DAIL, SALE, VEIL, HEEN, TEND, MOCK 66. TALL, YALL, FALL, HAUL, FOMS, REST, CRIB 67. THIEF, ZEEF, GRIEF, LEAF, VEGS, SWEAR, BITS 68. TRAIT, PAIT, WAIT, DATE, ZESK, LORD, NEWS 69. TYPE, DYPE, HYPE, PIPE, ZALS, DUCT, CROP 70. WEIGH, ZAY, NEIGH, HAY, ERM, AFFIX, LAP 71. WINE, BINE, SINE, SIGN, FOMP, FUSS, PARK 72. ZOO, NOO, WOO, TRUE, EFL, LAX, COST

(Manuscript received April 26, 1995 ;

revision accepted for publication November 30,1995 .) 